\title{
The availability, utilisation and relevance of therapeutic apparatuses in South African occupational therapy clinical practice
}

\author{
Catharina Maria Elizabeth Duvenage, B. Occ. Ther. (UFS); M. Augmentative and Alternative \\ Communication (UP) https://orcid.org/0000-0003-2524-0249 \\ Occupational Therapist, Ukwanda Centre for Rural Health, Stellenbosch University \\ Kopano Rebaona Dube, BSc. Human Life Science (SU); BSc. (Hons) Medical Virology (SU); MSc. Medical \\ Physiology (SU) https://orcid.org/0000-0002-6609-35 I6 \\ Research Intern, Ukwanda Centre for Rural Health, Stellenbosch University
}

*Anne Maria Rodrigues, B. Occ. Ther. (SU) https://orcid.org/0000-0002-2622-5297

Occupational Therapist, Jonas Occupational Therapy, Roodepoort, Johannesburg

*Alicia Swart, B. Occ. Ther. (SU). https://orcid.org/0000-0002-805 I-7848

Occupational Therapist, LIFE Health Care, Sandton

*Kelly Slater, B. Occ. Ther. (SU). https://orcid.org/0000-000 I-8895-2927

Occupational Therapist, Private Practice, KwaZulu Natal Midlands

*Undergraduate students, Department of Occupational Therapy, University of Stellenbosch at the time research was completed.

\section{INTRODUCTION}

The World Federation of Occupational Therapists (WFOT) steers the development, use and practice of occupational therapy internationally through numerous operations including policy and research in an effort to homogenise and advance occupational therapy training globally. The Federation has compiled and published the Minimum Standards for the Education of Occupational Therapists' that serves as a blueprint to both set the minimum standard for educational programmes in occupational therapy and to foster continuous quality assurance and professional development. In South Africa, the Professional Board for Occupational Therapy, Medical Orthotics and Prosthetics and Arts Therapy has incorporated these standards into the national policies and guidelines for occupational therapy training 2,3 . Consistent with international standards, one of the key outcomes highlighted in the national policies and guidelines is the graduate's knowledge of occupation. This key component is demonstrated by the "critical awareness of the 'Person-Occupation-Environment Relationship' relevant to the South African context" ${ }^{\prime 3: 8}$ and is measured through 17 criteria. The criteria include the graduate's skills in selecting the appropriate principles, strategies and technologies, (which comprise of assistive devices and therapeutic apparatuses) for promotive, preventative, palliative, therapeutic/care, rehabilitative interventions or programmes ${ }^{1,3}$. In light of the above, institutions offering occupational therapy training are required to select context appropriate technologies, to be referred to as therapeutic apparatus(es) from here onwards, to fulfil the listed outcome.

With eight South African academic institutions offering training in occupational therapy and very limited literature on therapeutic apparatus to guide training it becomes important to evaluate whether the theoretical and practical training offered on therapeutic apparatus is applicable in South African occupational therapy clinical practice. Consequently, the overall aim of this study was two-fold: first, to describe the therapeutic apparatus curriculum from the various institutions; second, to describe, the availability, utilisation and relevance of therapeutic apparatuses in South African occupational therapy clinical practice.

\section{METHODS}

The research design used was quantitative and consisted of two phases. In phase I the researchers contacted all eight academic institutions that offer occupational therapy training and requested the therapeutic apparatus course outline from either the occupational therapy undergraduate coordinators or lecturers who were responsible for teaching the therapeutic apparatus content. Institutions that did not respond or required the researchers to apply for ethical approval at their institution were excluded due to time constraints.

In phase 2 of the study, an online survey platform was used to design and distribute a survey to all Health Professions Council of South Africa (HPCSA) registered occupational therapists throughout South Africa. The survey consisted of a synopsis of the study, a consent form, and closed and open-ended questions that evaluated whether participants had received practical and theoretical training in therapeutic apparatus, as well as the primary sources of their knowledge about, and exposure to, therapeutic apparatuses. Furthermore, the survey queried the availability, utilisation and relevance of therapeutic apparatuses in the practitioners' current practice settings. To recruit all eligible participants, the survey was marketed through several social media platforms, including the Occupational Therapy Association of South Africa (OTASA) newsletter, Facebook and occupational therapy related networks. All the data and records received were anonymised and handled according to HPCSA guidelines for good practices ${ }^{4}$. The data were recorded, cleaned and analysed using SPSS for various measures of central tendency.

Ethical clearance was obtained for this descriptive study from the Undergraduate Research Ethics and Health Research Ethics 
Committees University of Stellenbosch (Ethics Clearance Number: UI7/0I/00I).

\section{RESULTS}

\section{Phase I}

Five $(\mathrm{N}=5)$ out of eight $(62 \%)$ occupational therapy training institutions participated in the study. In order to describe the therapeutic apparatus curriculum from the various institutions a comparative table was used to categorise the course outline according to four groupings namely, the definition of therapeutic apparatus and the source of the definition, the type of training offered on therapeutic apparatus, the classification of therapeutic apparatus content, and the therapeutic apparatuses included in training (See Table I below).

Two out of five (40\%) institutions specified a non-peer-reviewed definition (i.e. it had no academic reference/s) and source for therapeutic apparatus as well as a non-peer-reviewed classification system for the therapeutic apparatus content. Four out of five (80\%) institutions specified that they offered both theoretical and practical training and listed all the therapeutic apparatuses that they include in their academic training. The average of the five institutions was six apparatuses included in their therapeutic apparatus course outline, with one institution of the three having ten apparatuses and one institution of the three not specifying any apparatus. Therapeutic apparatuses that were frequently included in curricula of institutions (from highest to lowest frequency) included the Overhead Balance (OB) Help Arm $(n=4)$, Mobile Arm Support $(n=3)$, Tilt Table $(n=3)$, Motivational Therapeutic Apparatus $(n=3)$, Electronic Cycle $(n=2)$, Adjustable Tables $(n=2)$ and Standing Frame $(n=2)$.

\section{Phase 2}

The survey was sent to 4473 occupational therapists registered with the HPCSA, $949(21 \%)$ responses were recorded and 784 $(n=784)$ of these responses were valid and included in this analysis. Of these participants $569(72 \%)$ had between 3 to 20 years' clinical experience with $220(28 \%)$ providing services in physical health and II 7 (I5\%) providing services in mental health while 447 (57\%) participants provided either a combination of services in the community, work or medico legal settings. Six hundred and fifty eight $(84 \%)$ participants indicated that they received theoretical training about therapeutic apparatuses while $635(81 \%)$ indicated they received practical training. The three primary platforms (from highest to lowest frequency) where both practical and theoretical training were obtained included during undergraduate training ( $45 \%$ for both practical and theoretical), through workshops or courses ( $25 \%$ and $29 \%$ for practical and theoretical, respectively)

\section{Table I: Comparative table of institutional course outlines}

\begin{tabular}{|c|c|c|c|c|}
\hline Institution & $\begin{array}{l}\text { Definition of therapeutic apparatus } \\
\text { and Source of Definition }\end{array}$ & $\begin{array}{l}\text { Type of training } \\
\text { offered on therapeutic } \\
\text { apparatus }\end{array}$ & $\begin{array}{l}\text { Classification } \\
\text { of therapeutic } \\
\text { apparatus content }\end{array}$ & $\begin{array}{l}\text { Therapeutic apparatuses } \\
\text { included in training }\end{array}$ \\
\hline $\mathbf{A}$ & Not Specified & $\begin{array}{l}\text { Theoretical and Practical } \\
\text { Training }\end{array}$ & Not Specified & $\begin{array}{l}\text { MTA-ITS200M } \\
\text { Electronic Cycle } \\
\text { OB Help Arm } \\
\text { Mobile Arm Support } \\
\text { Therapeutic Furniture e.g. Hot } \\
\text { Box } \\
\text { Tilt Table }\end{array}$ \\
\hline B & Not Specified & $\begin{array}{l}\text { Theoretical arid Practical } \\
\text { Training }\end{array}$ & $\begin{array}{l}\text { I. Movement and } \\
\text { Exercise Apparatuses: } \\
\text { Electronic vs Mechanical } \\
\text { 2. Equipment }\end{array}$ & $\begin{array}{l}\text { I. Movement and Exercise } \\
\text { Apparatuses: } \\
\text { a. Electronic: } \\
\text { MTA } \\
\text { Electronic Cycle [Oliver] } \\
\text { b. Mechanical: } \\
\text { Wire Twister } \\
\text { FEPS } \\
\text { Lathe } \\
\text { 2. Equipment: } \\
\text { OB Help Arm } \\
\text { Standing Equipment } \\
\text { Tables with adjustable height } \\
\text { Mobile Arm Support } \\
\text { Standing Mirror } \\
\text { Other }\end{array}$ \\
\hline C & $\begin{array}{l}\text { "Apparati that are used in an } \\
\text { occupational section for treatment } \\
\text { purposes" - Lecture's Opinion }\end{array}$ & Not Specified & Not Specified & $\begin{array}{l}\text { OB Help Arm } \\
\text { Tilt Table } \\
\text { Standing Frame } \\
\text { MTA } \\
\text { Adjustable table/plinths } \\
\text { Hoist }\end{array}$ \\
\hline D & Not Specified & $\begin{array}{l}\text { Theoretical and Practical } \\
\text { Training }\end{array}$ & Not Specified & Not Specified \\
\hline $\mathbf{E}$ & $\begin{array}{l}\text { "Therapeutic apparati are used } \\
\text { together with activities to provide } \\
\text { meaning and purpose to treatment. } \\
\text { Thereby making the treatment session } \\
\text { therapeutic for the client. Therapeutic } \\
\text { apparatus has a variety of treatment } \\
\text { applications in the treatment of } \\
\text { sensory- motor problems." } \\
\text {-Informal Institutional definition }\end{array}$ & $\begin{array}{l}\text { Theoretical and Practical } \\
\text { Training }\end{array}$ & $\begin{array}{l}\text { I Suspension and } \\
\text { Related Apparatus } \\
\text { 2. Mechanical and } \\
\text { Electronic Apparatus }\end{array}$ & $\begin{array}{l}\text { I. Suspension and Related } \\
\text { Apparatuses: } \\
\text { OB Help Arm } \\
\text { Mobile Arm Support } \\
\text { 2. Mechanical and Electrical } \\
\text { Apparatuses: } \\
\text { Standing Frame } \\
\text { Tilt Table }\end{array}$ \\
\hline
\end{tabular}


and through manuals (13\% and I $4 \%$ for practical and theoretical, respectively). Almost all participants $(768 ; 98 \%)$ considered therapeutic apparatuses to be beneficial for client treatment, however only $580(74 \%)$ found it applicable to their current setting. Finally, only $470(60 \%)$ had access to therapeutic apparatuses that were in working order in their setting of which 395 (84\%) utilised it; 698 $(89 \%)$ of participants indicated that they would use therapeutic apparatuses if they had access.

\section{DISCUSSION}

Phase I of the study was dedicated to describing the therapeutic apparatus curriculum from all eight South African institutions that offer occupational therapy. Of the five institutions that participated in the study all, except one, specified that they provided both theoretical and practical training on therapeutic apparatus, while two institutions specified a non-peer-reviewed definition and classification system in both instances. Surprisingly, all the institutions had a comprehensive list of therapeutic apparatuses they included in their curriculum. Institutions that had a non-peer-reviewed classification system used it to inform the type of therapeutic apparatuses that were taught during occupational therapy training and classify it accordingly.

The findings of phase one present two arguments: Firstly, that a universal definition and classification system for therapeutic apparatuses may promote clarity and uniformity. The lack thereof leaves the definitions and classification systems subject to development by the institution or the educator. This not only results in institutional variations in terms of the type and amount of therapeutic apparatus content that is being taught, but also provides graduates with limited resources for further investigation on the topic. Consequently, the lack of a peer reviewed definition and classification system may hamper the growth of graduates' knowledge of therapeutic apparatuses. Secondly, the paucity of peer reviewed references leaves occupational therapists with inadequate resources for evidence and reference when patients or health professionals query the purpose, function and curative value of an apparatus this may subsequently restrict the effectiveness, efficiency and cost-effectiveness of the already limited occupational therapy services.

The process through which institutions select their therapeutic apparatus of choice for academic training could benefit from consistency within and amongst institutions. Consequently, the question arises of what should inform the type of therapeutic apparatus included in the occupational therapy therapeutic apparatus outline? Should it be policy, the global or national burden of disease, evidence of quality practices or the variety of clinical settings where occupational therapists offer their services - or all of the above? In addition, training institutions need to establish how many therapeutic apparatus items should be included during academic training to cultivate a well-rounded perspective in graduates. Institutions that developed a non-peer-reviewed definition and/ or classification system, had identified which apparatus is appropriate for inclusion according to their definition and/or classification system. This classification demonstrates the potential value of having structured or semi-structured definitions and/or classification systems. The latter argument is that rigid adherence to a single definition and classification system could stifle development subsequently, making the current curricula appropriate and easily adaptable for contextuallyrelevant development.

Phase 2 of the study aimed to describe the relevance of therapeutic apparatuses in South African clinical practice. A large number of participants, irrespective of their clinical experience or work setting, indicated that therapeutic apparatuses are beneficial and they would use it if they had access to it. Therapeutic apparatus is thus relevant in South African occupational therapy clinical practice and there may be a need to upscale access to context-specific therapeutic apparatuses that are in working order. The results of this study showed that there is potentially great value in developing and investing in therapeutic apparatuses for occupational therapy clinical practice. Collaborative research between institutions and various occupational therapy networks can serve as a possible solution to advancing the use of therapeutic apparatuses in both academic and clinical settings.

One limitation of the study is that the scope of the project did not allow for a formal systematic review of the literature on international practices in the use of therapeutic apparatuses this would been valuable for comparison to this study.

\section{REFERENCES}

I. World Federation of Occupational Therapists. Minimum Standards for the Education of Occupational Therapists - Revised. 2016; 2016. https://doi.org/10.1136/bmj.2.4518.222-a

2. Health Professions Council of South Africa. Professional Boards - HPCSA. 2018. Available at: http://www.hpcsa.co.za/PBOccupational/Guidelines. (Accessed: I7th July 20I8)

3. Health Professions Council of South Africa. Professional Board for Occupational Therapy, Medical Orthotics/Prosthetics and Arts Therapy. 2006; HPCSA, Pretoia.

4. Health Professions Council of South Africa. Confidentiality: Protecting and Providing Information. 2008; HPCSA, Pretoia.

\section{AUTHOR CONTRIBUTIONS}

Anne Rodrigues, Alicia Swart and Kelly Slater, students at the University of Stellenbosch conducted the research under the supervision of Catharina Duvenage. Kopano Dube and Catharina Duvenage conceptualised the study. All participants contributed to shaping the arguments in the article and writing the final submission.

\section{Corresponding Author}

CME Duvenage

Email:_miad@sun.ac.za 